Meta

Journal des tradlucteurs

Translators' Journal

\title{
Vie des néologismes
}

\section{Robert Dubuc}

Volume 13, numéro 4, décembre 1968

URI : https://id.erudit.org/iderudit/002614ar

DOI : https://doi.org/10.7202/002614ar

Aller au sommaire du numéro

Éditeur(s)

Les Presses de l'Université de Montréal

ISSN

0026-0452 (imprimé)

1492-1421 (numérique)

Découvrir la revue

Citer cet article

Dubuc, R. (1968). Vie des néologismes. Meta, 13(4), 188-190.

https://doi.org/10.7202/002614ar

Ce document est protégé par la loi sur le droit d'auteur. L'utilisation des services d'Érudit (y compris la reproduction) est assujettie à sa politique d'utilisation que vous pouvez consulter en ligne.

https://apropos.erudit.org/fr/usagers/politique-dutilisation/
Cet article est diffusé et préservé par Érudit.

Érudit est un consortium interuniversitaire sans but lucratif composé de l’Université de Montréal, l'Université Laval et l'Université du Québec à Montréal. Il a pour mission la promotion et la valorisation de la recherche. https://www.erudit.org/fr/ 


\section{PROBLÈMES ET SOLUTIONS}

\section{VIE DES NÉOLOGISMES}

Depuis longtemps, les chroniqueurs grammaticaux de la langue française s'en prennent aux hybrides, c'est-à-dire aux mots composés d'éléments empruntés à des langues diverses. À leurs yeux, seuls des mots comme philosophie (formé de deux racines grecques) ou comme matricide (formé de deux racines latines) devraient avoir droit de cité. Leurs foudres n'ont cependant pas empêché le foisonnement en français de ces formations qui depuis autobus jusqu'à télévision, en passant par homosexuel, génocide, autorail, aérogare et sociologie, forment le gros du contingent des néologismes de la langue contemporaine. La langue s'en porte-t-elle si mal? Est-ce un si grand crime que d'apposer une racine grecque à une racine latine, s'il en résulte un mot facilement utilisable ? La création d'automobile n'a pas été une catastrophe pour la langue française.

L'usager du français est en général prévenu contre le néologisme. M. Jean Darbelnet, citant Dauzat et Sauvy, nous le rappelait naguère ${ }^{1}$. Par un curieux paradoxe, ce même usager se fait très accueillant à l'emprunt. Alors qu'on exige des lettres de créances du néologisme autochtone, on ne requiert même pas un passeport pour le vocable d'emprunt. Plutôt que d'adjectiver le substantif « infirmier », on préfère accréditer l'emprunt nursing ${ }^{2}$. Il n'y a pas de plus sûr chemin pour l'anglicisation du français. Il vaut mieux alors tâcher de motiver le néologisme pour lui permettre de déloger l'emprunt. L'expérience montre que l'usager du français exige du néologisme qu'il laisse transparaître au moins sommairement sa signification. On comprend, dès lors, qu'on recoure assez facilement aux langues anciennes pour former des mots nouveaux dont les éléments sont d'ores et déjà identifiables. Mais comme la connaissance du grec et du latin devient de plus en plus rare, les mots ainsi formés ne répondent pas toujours aux exigences des philologues. Pourtant la langue française est en train de se doter ainsi d'un arsenal

1. * Ressources néologiques du français contemporain », META, vol. XII, nº 4, décembre 1967,

2. Cf. META, vol. XIII, n 3, septembre 1968, p. 139. 
de création néologique qui semble répondre à la fois aux exigences de l'usager moyen et aux nécessités de notre époque. Sur le modèle des formations étymologiques orthodoxes se créent des mots dont les éléments - s'écartant de leur valeur primitive - acquièrent une valeur nouvelle. Ainsi dans la lignée des dérivés d'auto: autoroute, autoneige ${ }^{3}$, autorail, autochenille, auto a laissé loin derrière lui son sens grec pour devenir une simple abréviation d'automobile ${ }^{4}$. Il en est de même de télé, abréviation de télévision, qui a engendré téléthéâtre (TV Drama), téléjournal (TV News), télégénique (apte à se produire à la télévision), téléradar (radar combiné à un écran de télévision).

L'aventure du suffixe -thèque n'est pas sans analogie avec les avatars de télé et d'auto. Du grec théca (coffre, lieu de rangement), cette racine, sous l'influence de bibliothèque, a fini par s'appliquer à un lieu où les choses sont classées de façon systématique, comme dans une bibliothèque. Le suffixe est donc à sa façon une abréviation, par la queue, de ce mot. On le soude à divers éléments identifiables: grecs, latins ou français. Toute une famille de mots est ainsi formée:

hémérothèque (newspaper library) où l'on conserve les journaux;

phonothèque (sound library), pour les enregistrements parlés;

cinémathèque (film library), pour les films;

discothèque (record library), pour les disques;

photothèque (still library), pour les photos;

musicothèque (music library), pour les feuilles de musique;

bandothèque ${ }^{5}$ (tape library), pour les bandes magnétiques;

sonothèque (sound effects library), qui désigne en radio l'endroit où l'on conserve les bruitages enregistrés.

L'étude de cette liste impressionnante nous amène à deux conclusions: la première, c'est qu'en dehors des spécialités, on n'a pas besoin d'un si grand nombre d'appellations spécifiques; la seconde, c'est que les formations « orthodoxes » sont souvent les moins vivantes: hémérothèque est un fossile, téniathèque qu'on a voulu substituer à bandothèque est une création mort-née et si phonothèque est bien en vie, ce n'est pas à son orthodoxie qu'il le doit, mais plutôt à la langue du commerce qui a vulgarisé le phonographe et le phono.

La vigueur d'un néologisme semble donc fonction d'abord et avant tout de sa motivation. Plus les éléments composants sont familiers, plus le néologisme a de chances de s'accréditer. Dans ces conditions, il serait dangereux d'imposer à la langue des mécanismes rigides de formation des néologismes qui n'engendreraient que des mots mort-nés. On ne doit pas tarir, pour des raisons logiques ou esthétiques souvent étrangères à la langue, l'une des sources de renouvellement qui va permettre à la langue française de traduire la réalité d'un monde en mouvement.

ROBERT DUBUC

3. En anglais snow mobile.

4. Marcel Galliot, les Nouvelles littéraires, 9 novembre 1961

5. L'expression s'applique à la fois aux bandes magnétiques et magnétoscopiques. On trouve aussi magnétothèque en ce sens. 